Wahana Didaktika Vol. 16 No.2 Mei 2018 : 162-172

\title{
ANALISIS DAN PERANCANGAN E-LEARNING ADAPTIF BERDASARKAN GAYA BELAJAR PADA MATA PELAJARAN SIMULASI DIGITAL DI SMK NEGERI 7 PONTIANAK
}

\author{
Oleh: Winna Dharmayanti ${ }^{1}$, Unung Verawardina ${ }^{2}$, Ratih Widya Nurcahyo ${ }^{3}$ \\ (Dosen IKIP PGRI Pontianak ) \\ Email :dharmayantiwinna@gmail.com
}

\begin{abstract}
Abstrak
Penelitian bertujuan untuk menganalisis dan perancangan media e-learning adaptif sesuai kebutuhan guru dan siswa berdasarkan gaya belajar pada mata pelajaran simulasi digital. Metode penelitian yang digunakan adalah jenis penelitian pengembangan (research and development) menggunakan model ADDIE dengan tahapan Analysis, Design, Development, Implementation dan Evaluation. Subjek pengembangan yakni ahli materi dan ahli media. Teknik pengumpul data menggunakan komunikasi langsung melalui alat panduan wawancara yang diberikan kepada siswa dan guru untuk mengetahui kebutuhan media e-learning adaptif berdasarkan gaya belajar. Kemudian teknik komunikasi tidak langsung melalui angket kelayakan produk media e-learning adaptif. Kesimpulan hasil penelitian yakni: (1) analisis media e-learning adaptif berdasarkan gaya belajar yang dibutuhkan adalah gaya belajar visual, auditori, dan kinestetik. (2) desain perancangan dengan membuat flowchart untuk menggambarkan alur dari perancangan media e-learning adaptif.
\end{abstract}

Kata Kunci : e-learning, adaptif, gaya belajar, simulasi digital

\section{ANALYSIS AND DESIGN OF ADAPTIVE E-LEARNING BASED ON LEARNING STYLE IN DIGITAL SIMULATION LESSONS IN SMK NEGERI 7 PONTIANAK}

\begin{abstract}
The study aims to analyze and design adaptive e-learning media according to the needs of teachers and students based on learning styles on digital simulation subjects. The research method used is the type of research development (research and development) using the ADDIE model with the stages of Analysis, Design, Development, Implementation and Evaluation. Development subject ie material experts and media experts. Data collection techniques use direct communication through interview guidance tools provided to students and teachers to find out the needs of adaptive e-learning media based on learning styles. Then indirect communication technique through questionnaire of feasibility of adaptive e-learning media product. Conclusion of research result that is: (1) analysis of adaptive e-learning media based on learning style needed is visual, auditory, and kinesthetic learning style. (2) design by creating a flowchart to illustrate the flow of adaptive e-learning media design.
\end{abstract}

Keywords: e-learning, adaptive, learning style, digital simulation. 
Analisis dan Perancangan E-Learning Adaptif....(Winna Dharmayanti)

\section{A. PENDAHULUAN}

Penggunaan Teknologi Informasi dan Komunikasi (TIK) telah memasuki ranah paradigma baru yakni proses pembelajaran tanpa dibatasi oleh jarak ruang dan waktu, yang tidak lagi hanya dibatasi pembelajaran konvensional di dalam kelas saja, akan tetapi dapat dilakukan dimanapun secara fleksibel. Sesuai dengan sistem pembelajaran di SMK yang dituntut untuk dapat belajar di sekolah maupun di dunia kerja dalam mempersiapkan lulusan yang terampil siap kerja, sehingga sangat tepat didukung dengan adanya sarana TIK yang mampu menunjang pembelajaran tersebut.

Salah satu peranan TIK untuk menunjang dalam pembelajaran tersebut dapat melalui pembelajaran online menggunakan e-learning. Menurut Sutopo (2012:143) e-learning merupakan suatu bentuk pembelajaran berbasis web yang dapat diakses dari internet atau intranet. E-learning mampu menyalurkan informasi dan memberi layanan interaksi di mana dan kapan saja, sehingga siswa dapat belajar secara luas secara fleksibel, selanjutnya dapat memberikan pengalaman belajar siswa agar mengusai keterampilan yang dipelajarinya melalui aktivitas yang tersedia di dalam e-learning.

Sistem e-learning yang baik dapat disesuaikan dengan faktor gaya belajar individu dalam proses pembelajaran. Gaya belajar secara umum dikenal dengan cara belajar siswa dalam belajar untuk memperoleh dan mengelolah informasi. Sistem e-learning yang dirancang menyesuaikan konsep gaya belajar penggunaanya yang dikenal dengan e-learning adaptif. E-learning adaptif adalah sistem e-learning yang mengadaptasi penyajian informasi dan struktur hubungan secara keseluruhan untuk pengguna sesuai karakteristik gaya belajar (Surjono, 2015:21). Oleh karena itu dengan e-learning adaptif dapat menyesuaikan gaya belajar siswa dalam belajarnya yang terdiri dari gaya belajar visual, auditori dan kinestetik.

Berdasarkan hasil pengamatan di SMK Negeri 7 Pontianak terungkap beberapa permasalahan yang terjadi yakni proses pembelajaran simulasi digital telah menggunakan media e-leaning, namun siswa masih belum aktif, belum adanya fasilitas interaksi untuk berkonsultasi anatara siswa dengan guru. 
Penyajian materi ajar hanya dikemas dalam bentuk video. Selain itu siswa cendrung belajarnya masih berpusat pada guru, terlihat siswa masih belum belajar mandiri menggunakan media e-learning, selain itu belum diperhatikannya gaya belajar siswa yang berbeda-beda dalam pembelajaran, keterampilan dan hasil belajar siswa masih rendah pada mata pelajaran simulasi digital.

Bertolak dari permasalahan tersebut maka dari itu peneliti menawarkan sebuah analisis dan perancangan media e-learning. Pentingnya penelitian ini untuk menganalsis media e-learning adaptif yakni dapat mengetahui kebutuhan siswa dan guru, menyesuaikan karakteristik gaya belajar siswa, menyesuaikan kebutuhan media dalam segi konsep sistemnya, tampilan media, navigasi, materi ajar, dan lain sebagainya.

Dalam penelitian ini menganalisis dan merancang media e-learning adaptif berdasarkan gaya belajar pada mata pelajaran simulasi digital menggunakan bahasa pemrograman web seperti php, html, javascript, dan database menggunakan PDOsql, materi pembelajaran dibuat dalam bentuk simulasi, audio dan video. Sehingga dapat menghasilkan e-learning adaptif berdasarkan gaya belajar siswa seperti visual, auditori dan kinestetik. Diharapkan dapat memberikan soluasi dari permasalahan yang terjadi di SMK Negeri 7 Pontianak, dalam mengatasi media sesuai kebutuhan, mengatasi keragaman gaya belajar siswa.

Pengembangan produk harus dirancang dengan baik, dengan menggunakan model ADDIE yang memiliki tahapan Analysis, Design, Development, Implementation dan Evaluation. Tujuan dari penelitian ini menghasilkan media e-learning adaptif sesuai kebutuhan guru dan siswa berdasarkan gaya belajar pada mata pelajaran simulasi digital

\section{B. METODOLOGI PENELITIAN}

Metode yang digunakan dalam penelitian ini merupakan metode pengembangan. Borg and Gall (1989:624) mengemukakan "research and development is a powerful strategy of improving practice. It is a process used to develop and validate educational products”. Berarti bahwa penelitian dan 
Analisis dan Perancangan E-Learning Adaptif....(Winna Dharmayanti)

pengembangan merupakan strategi ampuh meningkatkan praktek. Penelitian dan pengembangan merupakan proses yang digunakan untuk mengembangkan dan memvalidasi produk pendidikan. Rancangan penelitian ini menggunakan model pengembangan ADDIE (Analyze, Design, Develop, Implement, and Evaluate). Menurut Branch (2010:2) model ADDIE adalah desain model yang berbentuk siklus sistematis dan terdiri dari 5 tahapan. Adapun tahapan ADDIE adalah (1) Analyze (analisis), (2) Design (perancangan), (3) Development (pengembangan), (4) Implement (implementasi), dan (5) Evaluate (evaluasi).

Subjek dalam penelitian ini siswa dan guru utuk menganalisis kebutuhan terhadap produk yang akan dikembangkan. Teknik pengumpulan data dalam penelitian menggunakan teknik komunikasi langsung melalui wawancara, dan alat yang digunakan yakni panduan wawancara untuk mengetahui kebutuhan siswa dan guru mengenai media e-learning adaptif yang akan dikembangkan.

Teknik analisis data dalam penelitian ini mendeskripsikan hasil wawancara langsung dengan siswa dan guru maka hasil wawancara tersebut dideskripsikan untuk menganalisis kebutuhan pengguna sebagai landasan dasar dalam mengembangkan produk media e-learning adaptif berdasarkan gaya belajar pada mata pelajaran simulasi digital.

\section{HASIL DAN PEMBAHASAN}

Adapun hasil dari analisis dan perancangan media e-learning adaptif berdasarkan gaya belajar dijabarkan berdasarkan langkah-langkah model pengembangan produk ADDIE dengan tahapan Analysis (analisis), Design (desain), Development (pengembangan), Implementation (implementasi) dan Evaluation (evaluasi) sebagai berikut:

\section{Analisis Kebutuhan Media E-Learning Adaptif}

\section{a. Tahap Analysis (Analisis)}

Analisis kebutuhan untuk mengetahui kebutuhan yang dilakukan peneliti tentang analisis dan perancangan yang diinginkan SMK Negeri 7 
Pontianak, khususnya mahasiswa dan guru seperti jenis gaya belajar, tampilan media, desain media, navigasi, materi media, dan sebagainya. kebutuhan tersebut maka dilakukanya wawancara. Adapun hasil dari wawancara yang diperoleh yakni:

\section{1) Analisis Kebutuhan Siswa}

Berdasarkan hasil wawancara kepada siswa pada jurusan kelas pada jurusan TKJ, RPL dan multimedia. Analisis kebutuhan siswa yakni menginginkan pembuatan media e-learning adaptif sesuai gaya belajar visual dengan ilustrasi yang menarik, gambar yang jelas, contoh-contoh yang kongkrit. Untuk gaya belajar auditori seperti kejelasan suara, narasi sesuai materi. Untuk gaya belajar kinestetik seperti adanya simulasi langkah demi langkah dalam menjelaskan materi, adanya navigasi untuk dicobakan dalam mengsimulasikan materi pada mata pelajaran simulasi digital. Dibutuhkan pula penyajian materi yang menarik.

Diperoleh beberapa informasi pada media e-learning adaptif yang dibutuhkan siswa adalah sebagai berikut:

a) Pada tampilan media di susun secara menarik dengan adanya gambargambar, animasi, logo SMK, halaman yang simpel mudah digunakan dan responsive.

b) Navigasi yang diinginkan dibuat secara jelas, penamaan navigasi mudah dipahami, tombol menu navigasi dibuat bentuk horizontal.

c) Pada materi dibuat dalam banyak bentuk gambar melalui tayangan ilustrasi videol, audio, kejelasan teks, dilengkapi pula animasi.

Diperlukan berupa forum diskusi yang dapat digunakan untuk mendiskusikan topik-topik dalam materi ajar simulasi digital. Dan aktivitas chatting, agar siswa dapat berkomunikasi dengan guru.

\section{2) Analisis Kebutuhan Guru}

Membutuhkan media e-learning adaptif sesuai gaya belajar siswa, membutuhkan media sesuai pada mata pelajaran simulasi digital. Membutuhkan media yang mudah diakses. Membutuhkan media yang ada 
pengontrolan nilai siswa, memudahkan dalam membaharui bahan ajar. Serta ketersedian pelaporan dari hasil penggunaan media, klasifikasi hasil gaya belajar siswa. Sistem pendftaran pada media e-learning adaptif menggunakan Nomor induk siswa (NIS) dan NIP atau NUPTK pada guru.

Angket gaya belajar dibuat untuk mengklasifikasikan gaya belajar siswa dengan pertanyaaan yang menggambarkan gaya belajar visual, auditori dan kinestetik. Pertanyaan dibuat secara jelas dan mudah dipahami. Serta penjelasan dari hasil angket gaya belajar siswa.

a) Tampilan media dirancang dengan layout yang simpel, perpaduan warna yang kontras dan menarik, tampilan media didesain dengan gambar sekolah kejuruan SMKN 7 Pontianak, desain tampilan Tampilan icon mata pelajaran dirancang disesuaikan dengan mata pelajaran simulasi digital dengan kosep gaya belajar siswa, dengan diperjelas dengan tampilan logo gaya belajar.

b) Navigasi terdiri dari menu login, mata pelajaran, tugas, kuis, feedback dan ketersedian navigasi bantuan serta petunjuk penggunaan media. Dilengkapi juga alamat sekolah melalui maps. Navigasi dirancang dalam bentuk horizontal, vertical serta dengan dropdown).

c) Untuk menampilkan materi disajikan dalam bentuk gaya belajar visual menggunakan gambar dan ilustrasi melalui video. Sedangkan untuk gaya belajar auditori melalui narasi audio dan teks. Pada gaya belajar kinestetik dirancang dengan konsep simulasi. Materi yang digunakan pada pelajaran Simulasi digital adalah materi tentang membuat email dan membuat buku digital. Kompetensi intinya adalah memahami komunikasi dalam jaringan (daring online), mennyajikan hasil pemahaman tentang komunikasi dalam jaringan, menerapkan komunikasi dalam jaringan, menyajikan hasil penerapan komunikasi dalam jaringan. Dipilhnya kompetensi ini karena siswa masih merasa kesulitan memahami materi, selain itu juga siswa menginginkan konsep 
penyajian materi baru, serta nilai hasil belajar yang diperoleh siswa masih tergolong rendah.

d) Dibuthkan pula failitas chatting untuk berinteraksi antara siswa dan guru, untuk bertanya dan sharing kesulitan yang dihadapi oleh siswa. Dilengkapi dengan ketersediaan alat evaluasi berupa tugas yang dapat disampaikan kepada siswa dan siswa dapat mengirim tugas secara online, serta ketersedian kuis yang dapat diatur alokasi waktunya dan hasil skor yang diperoleh. Pada saat mengerjakan test diharapkan siswa tidak terhubung dengan web manapun sehingga hasil skor yang diperoleh siswa berdasarkan kemampuan siswa yang sesungguhnya tidak ada bantuan dari bentuk apapun. Setelah siswa mengerjakan kuis dan mengetahui hasilnya

\section{3) Analisis Kebutuhan Laboran}

Analisis kebutuha perangkat yang diperlukan adalah perangkat komputer, fasilitas internet. Untuk di SMK Negeri 7 Pontianak, sangat menunjang karena memiliki perangkat komputer yang memadai, terlebih yang dijadikan sasaran pengembangan produk adalah siswa yang jurusan TIK, seperti TKJ, RPL dan multimedia

Sedangkan untuk administrator yang digunakan sebagai sumberdaya untuk mengelolah media e-learning adaptif dapat melibatkan pengelolah laboratorium. Kesimpulan hasil wawancara yang diperoleh menyatakan bahwa sarana dan prasarana untuk menjalankan media elearning adaptif berdasarkan gaya belajar dapat mendukung.

\section{4) Analisis Kebutuhan Media E-learning Adaptif}

Berdasarkan hasil analisis kebutuhan pembuatan media e-learning adaptif berdasarkan gaya belajar diperlukannya peralatan komputer, jaringan internet, membutuhkan hosting dan domain untuk menyimpan file-file media e-learning adaptif dan materi. Sedangkan fasilitas yang dimiliki telah memadai mempunyai laboratorium komputer, internet dan merupakan salah satu sekolah yang menerapkan Ujian Nasional Berbasis 
Komputer (UNBK). Adapun spesifikasi untuk menjalan produk ini sebagai berikut:

a) Perangkat keras komputer menggunakan sistem operasi Windows.

b) Jaringan internet, mouse, touch ped, dan speaker untuk audio.

c) Web browser seperti Google Chrome

d) Panduan menggunakan produk, aplikasi pemutar audio dan video, serta aplikasi adobe flash.

\section{Perancangan Media E-learning adaptif}

\section{Tahap Design (Desain)}

Pada tahap ke dua dilakukanya desain yakni bersumber dari analisis kebutuhan yang kemudian didesain perancangannya. Maka diperlukan klarifikasi terhadap produk media e-learning adaptif tentang spesifikasi yang didesain, sehingga produk tersebut sesuai dengan yang dibutuhkan. Perancangan mulai dari flowchart yang bertujuan untuk memanajemen media e-learning adaptif. Berikut flowchart media e-learning adaptif. flowchart disesuaikan dengan sekolah dan siswa. 


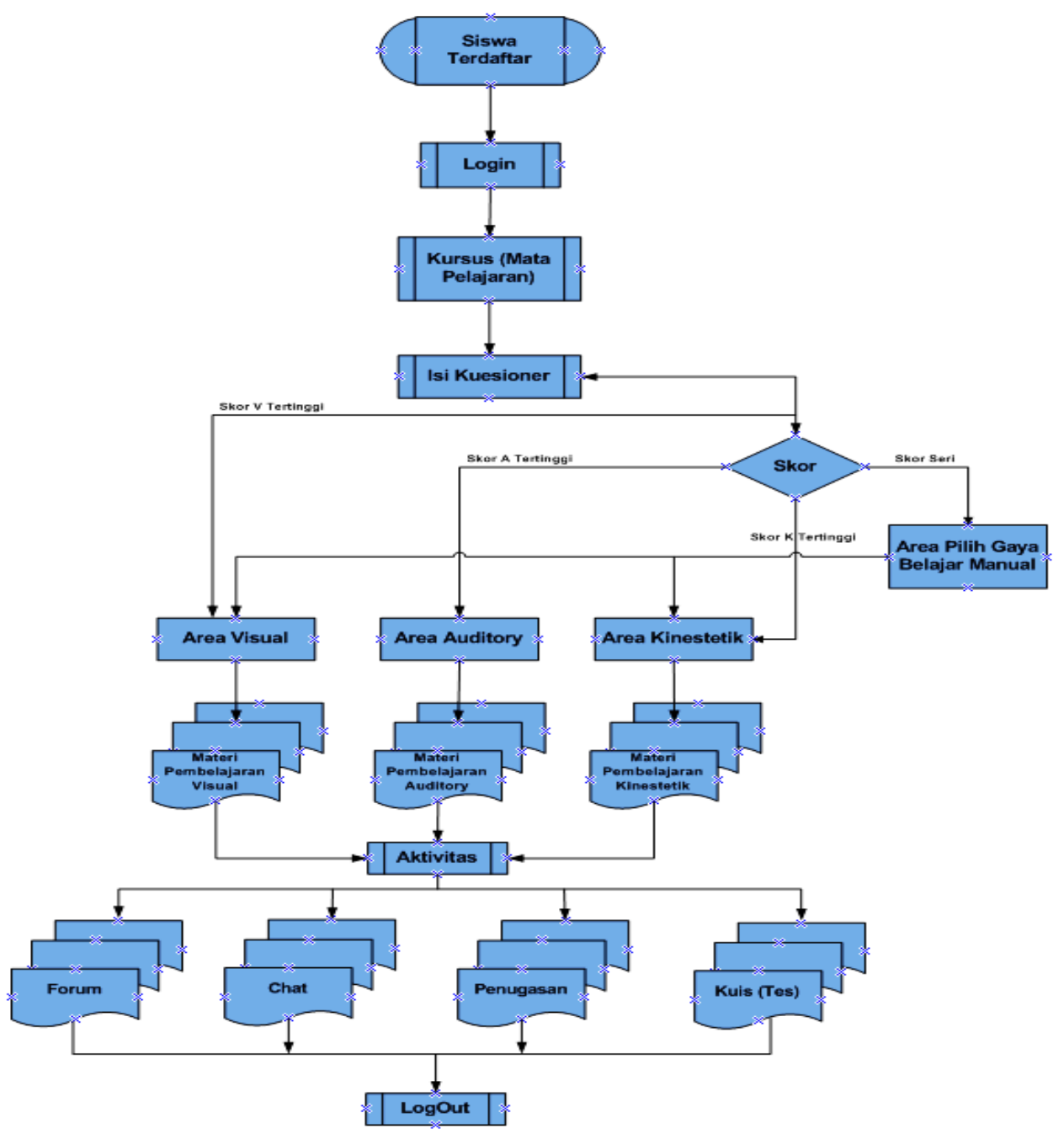

Gambar 1: Flowchart media e-learning adaptif

\section{PEMBAHASAN}

Pada analisis dan perancangan media e-learning adaptif berdasarkan gaya belajar pada mata pelajaran simulasi digital ini menggunakan jenis penelitian pengembangan dengan model ADDIE melalui tahapan Analysis (analisis), Design (desain), Development (pengembangan), Implementation (implementasi) dan Evaluation (evaluasi). 
Analisis dan Perancangan E-Learning Adaptif....(Winna Dharmayanti)

\section{Analisis Kebutuhan Media E-learning Adpatif}

Media e-learning adaptif berdasarkan gaya belajar memiliki kelebihan yakni dibuat menyesuaiakan analisis kebutuhan siswa dan guru. Berdasarkan hasil analisis kebutuhan media e-learning adaptif yang dibuat memperhatikan gaya belajar siswa bersifat visual, auditori dan kinestetik. Bagi guru yang mengajar mata pelajaran simulasi digital media e-learning adaptif sangat dibutuhkan oleh siswa dalam pemahaman materinya, tingkat kesulitan materi yang beragam membuat guru membutuhkan media e-learning adaptif sebagai wadah memperjelas materi yang disampaikan. Karena selama ini guru hanya mengajarkan menggunakan media kelas maya melalui media e-learning saja tidak sesuai dengan gaya belajar siswa. Dengan adanya media e-learning adaptif diharapkan dapat memotivasi siswa dalam belajar karena sesuai dengan masingmasing gaya belajar siswa. Karena selama ini siswa kurang termotivasi dalam belajar, kurangnya fasilitas ketersediaan gedget dan perangkat komputer dirumah, yang membuat siswa malas untuk mengerjakan tugas yang diberikan melalui kelas maya. Sehingga untuk tercapaian diperlukan analisis dan rancangan produk adalah media e-learning adaptif berdasarkan gaya belajar pada mata pepalajarn simulasi digital di SMK Negeri 7 Pontianak.

Kelebihan dari media $e$-learning adaptif berdasarkan gaya belajar ini adalah dibuat secara online agar dapat diakses dimana dan kapan saja tanpa dibatasi oleh jarak ruang dan waktu, selain itu dibuat dalam bentuk menyesuaikan gaya belajar siswa, seperti gaya belajar visual, auditori dan kinestetik Media e-learning adaptif yang menyesuaikan keragaman gaya belajar peserta didik yang dibuat sesuai kebutuhan terbukti bahwa dengan penerapan e-learning adaptif tersebut memiliki efektivitas dalam meningkatkan hasil belajar (Surjono, 2015:21). Oleh karena itu diharapkan dari analisis dan perancangan media e-leaning adaptif ini dapat memberikan soluasi dari permasalahan yang terjadi di SMK Negeri 7 Pontianak, dalam mengatasi media sesuai kebutuhan, mengatasi keragaman gaya belajar siswa serta meningkatkan hasil belajar siswa pada mata pelajaran simulasi digital. 
Wahana Didaktika Vol. 16 No.2 Mei 2018 : 162-172

\section{Perancangan Media E-learning Adpatif}

Untuk mendeskripsikan hasil perancangan media e-learning adaptif dibuatnya flowchart yang bertujuan untuk menggambarkan alur sistem dari media e-learning adaptif. Media e-learning adaptif dirancang dengan konsep desain tampilan yang menarik, simpel, perpaduan warna yang kontras satu sama lain. Perancangan produk adalah segala yang menjadi masukan kebutuhan guru dan siswa dari logo, botton feedback, petunjuk, chatt, forum, materi mata pelajaran, tugas hingga kuis.

\section{E. SIMPULAN}

Kesimpulan hasil penelitian dalam menganalisis dan perancangan media $e$ learning adaptif berdasarkan gaya belajar, dilakukan menggunakan model ADDIE dengan tahapan Analysis (analisis), Design (desain), Development (pengembangan), Implementation (implementasi) dan Evaluation (evaluasi). Namun dalam penelitian ini hanya pada tahapan analisis dan desain untuk mengetahu analisis dan perancangan produk. Hasilnya sebagai berikut: (1) tahap analisis untuk menganalisis kebutuhan siswa, dan guru pada media e-learning adaptif seperti tampilan, desain, navigasi, penyajian materi dan lain-lain; (2) tahap desain, yakni mendesain produk media e-learning adaptif sesuai dengan kebutuhan yang meliputi spesifikasi produk dan rancangan desain media $e$ learning adaptif, dirancang pula flowchart.

\section{DAFTAR PUSTAKA}

Branch, R. B. (2009). Instructional design: the addie approach: heidelberg. London: Springer.

Borg, W. R. \& Gall, M. D. 1986. Educational research, An Introduction (fifth edition). New York \& London: Longman.

Surjono, H.D. (April 2015). Adaptive and enganging e-learning inovasi pemanfaatan teknologi informasi dalam pendidikan jarak jauh makalah disampaikan dalam pidato Pengukuhan Guru Besar di Universitas Negeri Yogyakarta.

Sutopo, H.A. (2012). Teknologi informasi dan komunikasi dalam pendidikan. Yogyakarta: Graha Ilmu. 